\title{
Microwave-assisted Efficient Synthesis of Isatins and spiro- Thiadiazolines under Green Chemistry Protocol
}

\author{
H. M. Mamun ${ }^{1 *}$, M. A. Foysal ${ }^{1}$, M. Mahabub ${ }^{1}$, and Al-Amin ${ }^{2}$ \\ ${ }^{1}$ Department of Chemistry, Jahangirnagar University, Savar, Dhaka-1342, Bangladesh \\ ${ }^{2}$ Department of Synthetic Chemistry, Shoumachi, Tokushima University, 770-8505, Japan
}

Received 16 November 2009, accepted in final revised form 24 February 2010

\begin{abstract}
MW-assisted treatment of oximinoacetanilides obtained from substituted primary aromatic amines was carried out in conc. $\mathrm{H}_{2} \mathrm{SO}_{4}$ medium for 5-10 sec to give cyclic amides (isatins) through intramolecular cyclization by means of electrophilic aromatic substitution. Isatins reacted with thiosemicarbazide under MW-condition gave the corresponding Schiff-bases. The Schiff-bases undergo cyclization in presence of minimal $\mathrm{Ac}_{2} \mathrm{O}$ under MW-irradiation for 3-4 min to give the spiro-thiadiazoline acetyl derivatives in excellent yield.
\end{abstract}

Keywords: Microwave-synthesis; Isatins; Schiff-base; spiro-Thiadiazoline; Green chemistry.

(C) 2010 JSR Publications. ISSN: 2070-0237 (Print); 2070-0245 (Online). All rights reserved.

DOI: $10.3329 /$ jsr.v2i2.3731 J. Sci. Res. 2 (2), 322-329 (2010)

\section{Introduction}

It has long been known that molecules undergo excitation with electromagnetic radiation. This effect is utilized in household microwave ovens to heat up food. However, chemists have only been using microwaves as a reaction methodology for a few years. Some of the first examples gave amazing results, which led to a flood of interest in this novel technique $[1,2]$. In the last 10 years since the appearance of the first paper on organic synthesis under microwave (MW) dielectric heating, the field has expanded dramatically [3]. Chemistry in the $21^{\text {st }}$ century takes up the concept of scientific challenges of protecting the human health and the environment from the hazards posed by chemical processes. An excellent research effort to use MW for organic synthesis has been devoted over the last two decades [4]. This is because MW minimizes the formation of unwanted by-products and it reduces the need for organic solvents to a minimum or can even be used under solvent-free condition [5,6]. Oxindoles particularly isatins and their related

\footnotetext{
${ }^{*}$ Corresponding author: chemmamun2@yahoo.com
} 
compounds are important class of compounds due to their excellent biological effects, including antifungal, antiviral, and anti-proliferative activities [7]. In addition to that these compounds are very useful synthetic intermediates and can function as suitable building blocks to synthesize some other biologically active compounds such as natural products.

Hence a significant rising research interest in the design of oxindoles and spirothiadiazolines as drugs is currently observed in the field of medicinal organic chemistry [7]. The conventional synthesis of the similar type Schiff-bases and thiadiazoline derivatives of isatin derivatives and their consequent biological activities have been reported in many of ours and other previous articles [8-11]. Besides, MW-assisted synthesis of isatin related compounds in different ways is also reported [11]. Our present investigation will report on the synthesis of some indole-based heterocyclic compounds and spiro-thiadiazolines under MW-irradiation taking minimum solvent or almost solventfree conditions, which upholds the motto of green chemistry.

\section{Experimental}

Microwave reactor: A Microwave oven (power range: 0-650 $\mathrm{W}$ at $2.45 \mathrm{GHz}$, modified properly by fitting with a suitable condenser unit, a thermo-sensor, and thermostat, temperature range $40-250^{\circ} \mathrm{C}$, agitation: magnetic stirrer, Shikoku Instrumentation Co., Ltd Japan ) was used as a reaction apparatus. The temperature gradient of the reactor was 2$5^{\circ} \mathrm{C} / \mathrm{sec}$. The microwave was a modern reactor for carrying the transformations. Moreover, each and every reaction was carried out at least three times to ensure the reproducibility. Fisher-John's electrothermal melting point apparatus was used for recording the melting points of all the synthesized compounds by thin disc method and were not corrected. Infrared spectra were recorded on Fourier Transform Infra-red Spectrophotometer in $\mathrm{KBr}$ disc. ${ }^{1} \mathrm{H}-\mathrm{NMR}$ and ${ }^{13} \mathrm{C}-\mathrm{NMR}$ spectra were recorded on a Bruker AM 400MHz Spectrometer. The mass spectra were recorded on a Karatas MS-25.

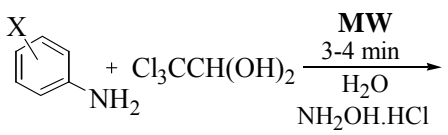

5a: $\mathrm{X}=3-\mathrm{Cl}$ 5b: $\mathrm{X}=4-\mathrm{Cl}$ 5c: $\mathrm{X}=\mathrm{H}$ $110^{\circ} \mathrm{C}$<smiles>[X]c1ccc(NC(=O)C=[No])cc1</smiles>

4a: $\mathrm{X}=3-\mathrm{Cl}$

4b: $\mathrm{X}=4-\mathrm{Cl}$

4c: $\mathrm{X}=\mathrm{H}$

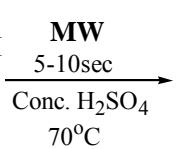<smiles></smiles>

3a: $\mathrm{X}=4-\mathrm{Cl}$ 3b: $\mathrm{X}=6-\mathrm{Cl}$ 3c: $\mathrm{X}=5-\mathrm{Cl}$ 3d: $X=H$

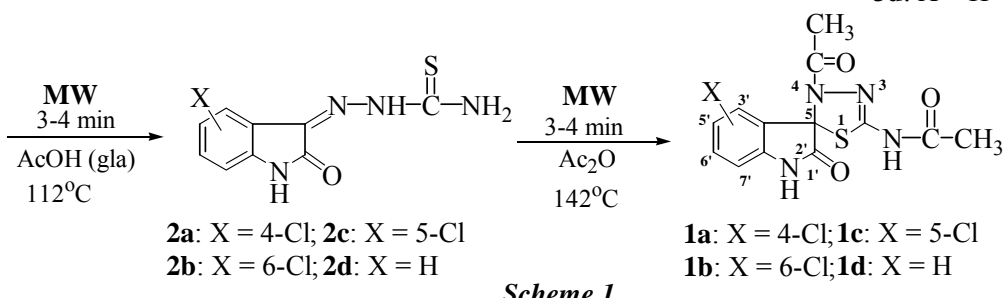

Scheme 1 


\subsection{Microwave-assisted general synthesis of substituted indole-2,3-diones (3a-d)}

Oximinoacetanilide 4a $(1.00 \mathrm{~g}, 5.04 \mathrm{mmol})$, obtained from aromatic amines as per literature [10] method, was mixed with concentrated sulfuric acid (3.3mL) and the resulting mixture was irradiated (20\% radiation of the total power) under microwave for $10 \mathrm{sec}$ [6]. The progress of the reaction was monitored by TLC $\left(\mathrm{CHCl}_{3}:\right.$ EtOAc, 3:1). Neutralization of the reaction mixture with $20 \% \mathrm{Na}_{2} \mathrm{CO}_{3}$ solution gave an orange solid mass. The solid was found to be a mixture of two compounds ( $840 \mathrm{mg}$, crude yield $92 \%$ ). The isomers were separated by using column chromatography and subsequent recrystallization from methanol and compounds $3 \mathbf{a}(532 \mathrm{mg}, 63 \%$ yield) and $3 \mathbf{b}$ (280 mg, $33 \%$ yield) were obtained.

\subsubsection{4-Chloro-indole-2,3-dione (3a)}

Compound 3a (4-chloroisatin): $\mathrm{mp}$ was $258-259^{\circ} \mathrm{C}$.

IR (KBr): $v_{\max }\left(\mathbf{c m}^{-1}\right)$ : 3342 (br, N-H, lactam), $3100(\mathrm{w}, \mathrm{C}-\mathrm{H}, \mathrm{Ar}), 1742(\mathrm{~s}, \mathrm{C}=\mathrm{O}$, lactam), 1735 (s, C=O, keto), 1611, 1496 (s, C=C, Ar). ${ }^{1}$ H-NMR (CD ${ }_{3}$ OD): $\delta 11.13$ (s, 1H, NH), 7.53-6.99 (m, 3H, ArH). ${ }^{13}$ C-NMR (CD OD) $_{3} \delta 186.13$ ( $\underline{\mathrm{C}}=\mathrm{O}$, ketone), 158.33 $(\underline{\mathrm{C}}=\mathrm{O}$, lactam), 141.81, 136.21, 134.36, 131.12, 126.42 and 120.32 (aromatic carbons). MS: $\mathrm{m} / \mathrm{z} 183 / 181\left(\mathrm{M}^{+}, 1: 3{ }^{35} \mathrm{Cl}, \mathrm{C}_{8} \mathrm{H}_{4} \mathrm{ClNO}_{2}\right)$.

\subsubsection{6-Chloro-indole-2,3-dione (3b)}

Compound $3 \mathbf{b}$ (6-chloroisatin): $\mathrm{mp}$ was $248-249^{\circ} \mathrm{C}$.

IR (KBr): $v_{\max }\left(\mathbf{c m}^{-1}\right): 3355(\mathrm{~N}-\mathrm{H}$, lactam), 3072 (w, C-H, Ar), 1742 (s, C=O, lactam), 1738 (s, C=O, keto), 1621, 1496 (s, C=C, Ar). ${ }^{1} \mathbf{H}-\mathbf{N M R}\left(\mathbf{C D}_{3} \mathbf{O D}\right): \delta 11.23$ (s, 1H, NH), $7.52\left(\mathrm{~d}, 1 \mathrm{H}, J_{\mathrm{m}}=1.7 \mathrm{~Hz}, \mathrm{C}_{7}-\mathrm{H}\right), 7.03\left(\mathrm{dd}, 1 \mathrm{H}, J_{\mathrm{o}}=7.3 \mathrm{~Hz}, J_{\mathrm{m}}=1.7 \mathrm{~Hz}, \mathrm{C}_{5}-\mathrm{H}\right), 6.96(\mathrm{~d}$, $\left.J_{\mathrm{o}}=7.3 \mathrm{~Hz}, \mathrm{C}_{4}-\mathrm{H}\right) .{ }^{13} \mathbf{C}-\mathbf{N M R}\left(\mathbf{C D}_{3} \mathbf{O D}\right): \delta 186.43(\underline{\mathrm{C}}=\mathrm{O}$, ketone), 159.21 ( $\underline{\mathrm{C}}=\mathrm{O}$, lactam$)$, $140.45,135.31,133.35,130.11,125.27$ and 119.97 (aromatic carbons). MS: m/z 183/181 $\left(\mathrm{M}^{+}, 1: 3{ }^{35} \mathrm{Cl}, \mathrm{C}_{8} \mathrm{H}_{4} \mathrm{ClNO}_{2}\right)$.

\subsubsection{5-Chloro-indole-2,3-dione (3c) [12]}

\subsubsection{Indole-2,3-dione (3d)}

Compound 3d: (351 mg, 78.5\%), mp was $198-200^{\circ} \mathrm{C}$ (decomp.)

IR KBr: $v_{\max }\left(\mathbf{c m}^{-1}\right): 3324$ (s, N-H, lactam), 3070 (w, C-H, Ar), 1742 (s, C=O, lactam), $1714\left(\mathrm{C}=\mathrm{O}\right.$, keto), 1608, $1472(\mathrm{C}=\mathrm{C}, \mathrm{Ar}) .{ }^{1} \mathbf{H}-\mathbf{N M R}\left(\mathbf{C D}_{3} \mathbf{O D}\right): \delta 10.71$ (s, 1H, NH), 7.636.98 (m, 4H, ArH). ${ }^{13}$ C-NMR (CD $\left.{ }_{3} \mathbf{O D}\right): \delta 187.43$ ( $\underline{\mathrm{C}}=\mathrm{O}$, ketone), 156.78 ( $\underline{\mathrm{C}}=\mathrm{O}$, lactam), 138.56, 134.81, 132.65, 129.21, 123.27 and 120.7 (aromatic carbons). MS: m/z $147\left(\mathrm{M}^{+}\right.$, $\mathrm{C}_{8} \mathrm{H}_{5} \mathrm{NO}_{2}$ ). 


\subsection{Microwave-assisted general synthesis of thiosemicarbazones (2a-d) from compounds $3 a-d$}

Compound 3a (170.4 mg, $0.94 \mathrm{mmol})$ was taken in a mixture of thiosemicarbazide (86.81 $\mathrm{mg}, 0.95 \mathrm{mmol})$ and glacial acetic acid $(3.5 \mathrm{~mL})$ and the reaction mixture was irradiated under microwave for $50 \mathrm{sec}$. The progress of the reaction was monitored by TLC (EtOAc:Hexane, 1:4). The reaction mixture was cooled to room temperature. A yellow solid was obtained, which was filtered off and washed with hexane and recrystallized from methanol to give 2a as a pale yellow crystalline solid.

2.2.1. 4-Chloro-3-thiosemicarbazono-1,3-dihydro-indol-2-one (2a)

Compound 2a: (202.32 mg, 85\%), mp was $268-270^{\circ} \mathrm{C}$.

IR (KBr): $v_{\max }\left(\mathbf{c m}^{-1}\right): 3315$ (w, N-H, lactam), 3115 (w, C-H, Ar), 1722 (s, C=O, lactam), 1690 (s, C=O, amide), 1623 (s, C-N), 1493, 1558 (s, C=C, Ar), 1133 (s, C-S). ${ }^{1}$ H-NMR (DMSO): $\delta 12.35\left(\mathrm{~s}, 1 \mathrm{H}\right.$, lactam NH), $11.30(\mathrm{~d}, 1 \mathrm{H}$, amide $\mathrm{NH}), 8.69\left(\mathrm{~s}, 2 \mathrm{H}, \mathrm{S}=\mathrm{C}-\mathrm{NH}_{2}\right)$, 7.83-6.92 (m, 3H, ArH). ${ }^{13}$ C-NMR (DMSO): $\delta 178.69(\mathrm{~S}=\underline{\mathrm{C}}-\mathrm{N}), 162.57(\mathrm{O}=\underline{\mathrm{C}}), 143.43$, 135.19, 130.94, 125.54, 122.27 and 118.98 (aromatic carbons). MS: m/z 256/254 (M $\mathrm{M}^{+}, 1: 3$ $\left.{ }^{35} \mathrm{Cl}, \mathrm{C}_{9} \mathrm{H}_{7} \mathrm{ClN}_{4} \mathrm{OS}\right)$.

\subsubsection{6-Chloro-3-thiosemicarbazono-1,3-dihydro-indol-2-one (2b)}

Compound 2a): (310.86 mg, $86 \%$ ), $\mathrm{mp}$ was $278-280^{\circ} \mathrm{C}$.

IR (KBr): $v_{\max }\left(\mathbf{c m}^{-1}\right): 3385$ (s, N-H), 3067 ( br, C-H, Ar), 1743 (s, C=O, lactam), 1690 (s, C=O, amide), 1639 (s, C-N), 1493 (s, C=C, Ar), 1133 (w, C-S). ${ }^{1}$ H-NMR (DMSO): $\delta 12.76(\mathrm{~s}, 1 \mathrm{H}, \operatorname{lactam} \mathrm{NH}), 11.43(\mathrm{~s}, 1 \mathrm{H}$, amide $\mathrm{NH}), 9.19\left(\mathrm{~s}, 2 \mathrm{H}, \mathrm{S}=\mathrm{C}-\mathrm{NH}_{2}\right), 7.81(\mathrm{~d}, 1 \mathrm{H}$, $\left.J_{\mathrm{m}}=1.8 \mathrm{~Hz}, \mathrm{C}_{7}-\mathrm{H}, \mathrm{ArH}\right), 7.30\left(\mathrm{dd}, 1 \mathrm{H}, J_{\mathrm{o}}=8.0 \mathrm{~Hz}, J_{\mathrm{m}}=1.8 \mathrm{~Hz}, \mathrm{C}_{5}-\mathrm{H}, \mathrm{ArH}\right), 6.96(\mathrm{~d}, 1 \mathrm{H}$, $\left.J_{\mathrm{o}}=8.0 \mathrm{~Hz}, \mathrm{C}_{4}-\mathrm{H}, \mathrm{ArH}\right) .{ }^{13} \mathrm{C}-\mathrm{NMR}$ (DMSO): $\delta 178.63$ ( $\left.\mathrm{S}=\mathrm{C}-\mathrm{NH}, \mathrm{C}-9\right), 162.26(\mathrm{O}=\underline{\mathrm{C}})$, $153.75(\mathrm{~N}=\mathrm{C}), 148.34,143.59,132.07,131.22,127.87$ and 123.45 (aromatic carbons). MS: $\mathrm{m} / \mathrm{z} 256 / 254\left(\mathrm{M}^{+}, 1: 3{ }^{35} \mathrm{Cl}, \mathrm{C}_{9} \mathrm{H}_{7} \mathrm{ClN}_{4} \mathrm{OS}\right)$.

\subsubsection{5-Chloro-3-thiosemicarbazono-1,3-dihydro-indol-2-one (2c)}

Compound 2a: (412.6 mg, 98\%), mp was $237-238^{\circ} \mathrm{C}$.

IR KBr: $v_{\max }\left(\mathbf{c m}^{-1}\right): 3345$ (w, N-H), 3100 (w, C-H, Ar), 1698 (s, C=O lactam), 1690 (s, $\mathrm{C}=\mathrm{O}$, amide), 1623 (s, C-N), 1558, 1493 (C=C, Ar), 1133 (s, C-S). ${ }^{1}$ H-NMR (DMSO): $\delta 12.29(\mathrm{~s}, 1 \mathrm{H}, \operatorname{lactam} \mathrm{NH}), 11.27(\mathrm{~d}, 1 \mathrm{H}$, amide $\mathrm{NH}), 8.70\left(\mathrm{~s}, 2 \mathrm{H}, \mathrm{S}=\mathrm{C}-\mathrm{NH}_{2}\right), 7.72(\mathrm{~d}, 1 \mathrm{H}$, $\left.J_{\mathrm{m}}=1.7 . \mathrm{Hz}, \mathrm{C}_{4}-\mathrm{H}, \mathrm{ArH}\right), 7.35\left(\mathrm{dd}, 1 \mathrm{H}, J_{\mathrm{o}}=7.8 \mathrm{~Hz}, J_{\mathrm{m}}=1.7 \mathrm{~Hz}, \mathrm{C}_{6}-\mathrm{H} \quad \mathrm{ArH}\right), 6.95(\mathrm{~d}, 1 \mathrm{H}$, $\left.J_{\mathrm{o}}=1.7 \mathrm{~Hz}, \mathrm{C}_{7}-\mathrm{H}, \mathrm{ArH}\right) .{ }^{13} \mathrm{C}-\mathrm{NMR}$ (DMSO): $\delta 178.78(\mathrm{~S}=\underline{\mathrm{C}}-\mathrm{NH}), 162.37(\mathrm{O}=\underline{\mathrm{C}}), 170.36$ $(\mathrm{N}=\underline{\mathrm{C}}), 140.94,130.77,129.40,126.52,121.88$ and 120.62 (aromatic carbons). MS: $\mathrm{m} / \mathrm{z}$ $256 / 254\left(\mathrm{M}^{+}, 1: 3{ }^{35} \mathrm{Cl}, \mathrm{C}_{9} \mathrm{H}_{7} \mathrm{ClN}_{4} \mathrm{OS}\right)$. 


\subsubsection{3-Thiosemicarbazono-1,3-dihydro-indol-2-one (2d)}

Compound 2a: (714.4 mg, 74\%), mp was $293-295^{\circ} \mathrm{C}$ (decomp.).

IR (KBr): $v_{\max }\left(\mathbf{c m}^{-1}\right): 3417$ (w, N-H amine/amide), 3035 (C-H, Ar), 2972, 2877 (C-H, aliphatic), 1708 (m, C=O, lactam), 1681 (s, C=N), 1611 (s, C=O, amide), 1125 (C-S). ${ }^{1} \mathrm{H}-$ NMR (DMSO): $\delta 12.46$ (s, 1H, lactam NH), 11.18 (d, 1H, amide NH), 8.66 (s, 2H, S=C$\left.\mathrm{NH}_{2}\right), 7.34-6.92$ (m, 4H, ArH). ${ }^{13} \mathrm{C}-\mathrm{NMR}$ (DMSO): $\delta 177.23(\mathrm{~S}=\mathrm{C}-\mathrm{H}), 164.58(\underline{\mathrm{C}}=\mathrm{O})$, $151.84(\underline{\mathrm{C}}=\mathrm{N}), 143.61,132.67,127.43,125.52,122.06$ and 115.15 (aromatic carbons). MS: $\mathrm{m} / \mathrm{z} 220\left(\mathrm{M}^{+}, \mathrm{C}_{9} \mathrm{H}_{8} \mathrm{~N}_{4} \mathrm{OS}\right)$.

\subsection{Microwave-assisted general synthesis of 5-spiro- $N$-acetyl-1,3,4-thiadiazoline (1a-d)}

Compound 2a (135.14 mg, $0.53 \mathrm{mmol})$ and freshly distilled acetic anhydride $(2.5 \mathrm{~mL})$ were irradiated under microwave for 3.5 minutes. The progress of the reaction was monitored by TLC (EtOAc: $\mathrm{CHCl}_{3}, 1: 3$ ). The reaction mixture was cooled to room temperature. A yellow solid was obtained, which was filtered off and crude solid was recrystallized from $\mathrm{MeOH}$ to give $\mathbf{1 a}$.

\subsubsection{5-Spiro-4'-chloroisatin-4-N-acetyl-2-(N-acetylamino)- $\Delta^{2}-1,3,4$-thiadiazoline (1a)}

Compound 2a: (168.5 mg, 93\%), mp was $241-242^{\circ} \mathrm{C}$

IR (KBr): $v_{\max }\left(\mathbf{c m}^{-1}\right): 3350$ (w, N-H), 3050 (m, C-H, Ar), 2960 (w, C-H, aliphatic), 1708 (w, C=O lactam), 1677 (s, C=O, acetyl), 1560 (s, C=C, Ar), 1458 (s, C-H), 1278 (s, C-N), 1150 (s, C-S). ${ }^{1} \mathbf{H}-\mathbf{N M R}$ (CD $\left.\mathbf{C D}_{3} \mathbf{O D}\right): \delta 12.77$ (s, 1H, lactam NH), 9.05 (s, 2H, S=C-NH${ }_{2}$ ), 7.62-6.93 (m, 3H, ArH), $2.08\left(\mathrm{~s}, 3 \mathrm{H}, \mathrm{COCH}_{3}\right), 1.98\left(\mathrm{~s}, 3 \mathrm{H}, \mathrm{NHCOCH}_{3}\right) .{ }^{13} \mathbf{C}-\mathbf{N M R}$ (CD $\left.{ }_{3} \mathbf{O D}\right): \delta 174.31,170.24$ and $166.42(3 \times \underline{\mathrm{C}}=\mathrm{O}$, lactam and amide), 144.33, 138.71, 136.21, 131.12, 126.42 and 120.32 (aromatic carbons), 64.32 (spiro C-5), 18.53 and 14.41 $\left(2 \times \mathrm{CH}_{3}\right)$. MS: $\mathrm{m} / \mathrm{z} 340 / 338\left(\mathrm{M}^{+}, 1: 3{ }^{35} \mathrm{Cl}, \mathrm{C}_{13} \mathrm{H}_{11} \mathrm{ClN}_{4} \mathrm{O}_{3} \mathrm{~S}\right)$.

\subsubsection{5-Spiro-6'-chloroisatin-4- $N$-acetyl-2-(N-acetylamino)- $\Delta^{2}-1,3,4$-thiadiazoline (1b)}

Compound 1b: (194.6 mg, 95\%), mp was $252-253^{\circ} \mathrm{C}$.

IR (KBr): $v_{\max }\left(\mathbf{c m}^{-1}\right): 3312(\mathrm{w}, \mathrm{N}-\mathrm{H}), 3050$ (br, C-H, Ar), 2957, 2872 (C-H, aliphatic), $1762(\mathrm{C}=\mathrm{O}$ lactam), $1722(\mathrm{C}=\mathrm{O}$, acetyl), 1617 (br, C=C, Ar), 1288 (s, C-N), 1166 (s, CS). ${ }^{1}$ H-NMR (DMSO): $\delta 12.29(\mathrm{~s}, 1 \mathrm{H}$, lactam NH), 8.78 (s, amide), $7.72(\mathrm{~d}, 1 \mathrm{H}$, $\left.J_{\mathrm{m}}=1.7 \mathrm{~Hz}, \mathrm{C}_{7}-\mathrm{H}, \mathrm{ArH}\right), 7.35\left(\mathrm{dd}, 1 \mathrm{H}, J_{\mathrm{o}}=8.2 \mathrm{~Hz}, J_{\mathrm{m}}=1.7 \mathrm{~Hz}, \mathrm{C}_{5}-\mathrm{H} \mathrm{ArH}\right), 6.91(\mathrm{~d}, 1 \mathrm{H}$, $\left.J_{\mathrm{o}}=8.2 \mathrm{~Hz}, \mathrm{C}_{4}-\mathrm{H}, \mathrm{ArH}\right), 2.49\left(\mathrm{~s}, 3 \mathrm{H}, \mathrm{COCH}_{3}\right), 2.12\left(\mathrm{~s}, 3 \mathrm{H}, 3 \mathrm{H}, \mathrm{COCH}_{3}\right) .{ }^{13} \mathbf{C}-\mathbf{N M R}$ (CD ${ }_{3}$ OD): $\delta 173.52,168.63$ and $165.42(3 \times \mathrm{C}=\mathrm{O}$, lactam and amide), 141.54, 137.11, 136.21, 130.12, 126.42 and 120.32 (aromatic carbons), 62.31 (spiro C-5), 19.87 and 15.11 $\left(2 \times \mathrm{CH}_{3}\right)$. MS: $\mathrm{m} / \mathrm{z} 340 / 338\left(\mathrm{M}^{+}, 1: 3{ }^{35} \mathrm{Cl}, \mathrm{C}_{13} \mathrm{H}_{11} \mathrm{ClN}_{4} \mathrm{O}_{3} \mathrm{~S}\right)$. 


\subsubsection{5-Spiro-5'-chloroisatin-4-N-acetyl-2-(N-acetylamino)- $\Delta^{2}-1,3,4$ - thiadiazoline (1c)}

Compound 1c: (126.6 mg, 80\%), mp was $248-250^{\circ} \mathrm{C}$.

IR (KBr): $v_{\max }\left(\mathrm{cm}^{-1}\right): 3437$ (w, N-H), 3050 (w, C-H, Ar), 2934 (w, C-H, aliphatic), 1678 (s, C=O, lactam), 1625 (s, C=O, acetyl), 1508 (s, C=C, Ar), 1462, 1380 (C-H), 1178 (s, CN). ${ }^{1} \mathrm{H}-\mathrm{NMR}$ (DMSO): $\delta 11.98(\mathrm{~s}, 1 \mathrm{H}$, lactam NH), 10.77 (s, 1H, amide $\mathrm{NH}), 8.70(\mathrm{~s}, 2 \mathrm{H}$, $\left.\mathrm{S}=\mathrm{C}-\mathrm{NH}_{2}\right), 7.54\left(\mathrm{~d}, 1 \mathrm{H}, J_{\mathrm{m}}=1.6 \mathrm{~Hz}, \mathrm{C}_{4}-\mathrm{H}, \mathrm{ArH}\right), 7.24\left(\mathrm{dd}, 1 \mathrm{H}, J_{\mathrm{o}}=8.0 \mathrm{~Hz}, J_{\mathrm{m}}=1.6 \mathrm{~Hz}, \mathrm{H}_{6}\right.$, $\mathrm{ArH}), 6.78\left(\mathrm{~d}, 1 \mathrm{H}, J_{\mathrm{o}}=8.0 \mathrm{~Hz}, \mathrm{C}_{7}-\mathrm{H}, \mathrm{ArH}\right), 2.32\left(\mathrm{~s}, 3 \mathrm{H}, \mathrm{COCH}_{3}\right) .2 .09$ (s, 3H, $\left.\mathrm{COCH}_{3}\right)$. ${ }^{13} \mathrm{C}-\mathrm{NMR}$ (DMSO): $\delta 172.46,170.21,167.18(3 \times \mathrm{C}=\mathrm{O}$, lactam and amide), 143.98, 137.91, 130.18, 129.73, 123.90, and 117.27 (aromatic carbons), 74.56 (spiro C-5), 22.75, 22.24 $\left(2 \times \mathrm{CH}_{3}\right)$. MS: $\mathrm{m} / \mathrm{z} 340 / 338\left(\mathrm{M}^{+}, 1: 3{ }^{35} \mathrm{Cl}, \mathrm{C}_{13} \mathrm{H}_{11} \mathrm{ClN}_{4} \mathrm{O}_{3} \mathrm{~S}\right)$.

\subsubsection{5-Spiro-isatin-4-N-Acetyl-2-(N-acetylamino)- $\Delta^{2}-1,3,4$-thiadiazoline (1d)}

Compound 1d: (282 mg, 97\%), mp was $300^{\circ} \mathrm{C}$ (decomp.).

IR (KBr): 3417 (w, N-H), 3167 (=C-H, Ar), 2950, 2850 (C-H, aliphatic), 1812 (s, C=O lactam), 1694 (s, C=O, amide), 1616 (br, C=C, Ar), 1492, $1333(\mathrm{C}-\mathrm{H}), 1175$ (s, C-N). ${ }^{1} \mathbf{H}-$ NMR (DMSO): $\delta 11.96$ (s, 1H, lactam NH), 10.69 (s, 1H, amide NH), 7.30-6.83 (m, 4H, ArH), 2.08 (s, 3H, H), 1.98 (s, 3H, H); ${ }^{13}$ C-NMR (DMSO): $8173.26,169.94,166.85$ $(3 \times \mathrm{C}=\mathrm{O}$, lactam and amide $), 142.68(\mathrm{~N}=\mathrm{C}, \mathrm{C}-9), 141.06,130.04,128.55,123.81,122.52$, 110.24 (aromatic carbons), 74.58 (spiro C-5), 22.29, $22.10\left(2 \times \mathrm{CH}_{3}\right) . \mathrm{MS}: \mathrm{m} / \mathrm{z} 304\left(\mathrm{M}^{+}\right.$, $\left.\mathrm{C}_{13} \mathrm{H}_{12} \mathrm{~N}_{4} \mathrm{O}_{3} \mathrm{~S}\right)$

\section{Results and Discussions}

Synthesis of oximinoacetanilides 4a-c from primary aromatic amines under MW irradiation was achieved almost solvent-free condition. The subsequent ring closure reaction of 4a-c with conc. $\mathrm{H}_{2} \mathrm{SO}_{4}$ to give 3a-c was also carried out in a nice manner under $\mathrm{MW}$-condition in high yields for $10 \mathrm{sec}$. It is worth to be noted that the interaction of $\mathrm{H}_{2} \mathrm{SO}_{4}$ with MW irradiation was found to be unfriendly. Specially prolong exposure of MW radiation to the reaction mixture was harmful because it decomposed the products. Resultantly a charring occurred and gave a black decomposed reaction mixture. To prevent the reaction mixture from scorching a short pulse irradiation technique was applied (5 sec/irradiation) instead of a long one. Just two $5 \mathrm{sec}$ pulses of MW-irradiation completed the cyclization and gave expected yield of the corresponding isatins 3a-d. As predicted, conc. $\mathrm{H}_{2} \mathrm{SO}_{4}$ mediated cyclization of $\mathbf{4 a}$ under $\mathrm{MW}$ condition gave a mixture of isomeric isatins $\mathbf{3 a}$ and $\mathbf{3} \mathbf{b}$. The separation of both the isomers was carried out successfully by column chromatography using hexane and ethyl acetate (3:1) as eluent. The ratio of $\mathbf{3 a}$ to $\mathbf{3} \mathbf{b}$ was found to be $2: 1$. It is presumably due to the weaker inductive effect of chlorine atom at its ortho position compared to para, facilitated the ring closure at ortho position in a faster rate and hence gave $3 \mathbf{a}$ as a major product. Similarly compound $\mathbf{3 c}$ was obtained as a sole product from $\mathbf{4 b}$ through cyclization. 


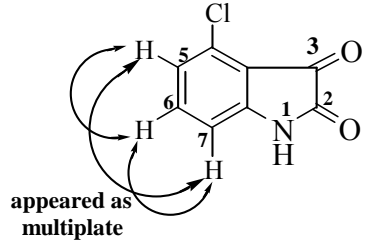

3a

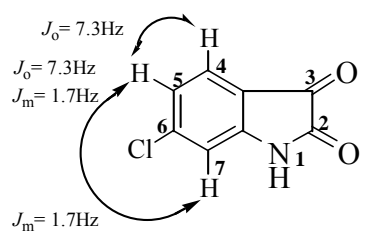

$3 \mathbf{b}$

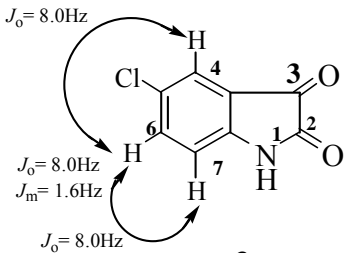

3c

Scheme 2

${ }^{1} \mathrm{H}-\mathrm{NMR}$ spectra of cyclized compounds are substantially explicable and the pattern of $\mathrm{H}-\mathrm{H}$ coupling is shown in Scheme 2. ${ }^{13} \mathrm{C}-\mathrm{NMR}$ of both the isomers showed eight clear signals. For compound 3a the lactam carbon appeared at $\delta 158.33$ and the carbonyl carbon at $\delta 186.13$. The aromatic carbon attached to chlorine appeared at $\delta 134.36$. Other aromatic carbons appeared at $\delta 141.81,136.21,131.12,129.21$ and 126.42 respectively. The reaction of oxindoles with thiosemicarbazide under $\mathrm{MW}$-irradiation gave the corresponding Schiff-bases 2a-d in very high yields. Compounds 2a-d showed clear broad peaks in the ${ }^{1} \mathrm{H}-\mathrm{NMR}$ spectra at around $\delta: 12.00 \mathrm{ppm}$ for lactam $\mathrm{NH}$. The intramolecular cyclization of Schiff bases in presence of glacial AcOH was carried out under MWcondition for 3-4 min in very high yields. The formation of the spiro heterocyles 1a-d can easily be understood by their ${ }^{1} \mathrm{H}-\mathrm{NMR}$ spectra (peaks due to lactam $\mathrm{NH}$ around $\delta 11-12$ and for $\mathrm{COCH}_{3} \delta 2-2.5$ respectively).

\section{MW technique - faster reaction with minimum solvent - green cChemistry protocol}

MW-dielectric heating, a state-of-the-art tool, and its non-thermal effects play an important role in the formation of molecule in high yields in short time compared to the reactions carried out in classical heating method. But there is no concrete clarification of these observations. Without exception we were able to achieve very high yields in our synthesis of oxindole based important heterocycles. In addition, almost every reaction was carried out with minimal solvent. Actually solvent-free condition was highly favorable in the MW reaction because the electric vector of the radiation interacts with polar solvent and hence the reactant gets the energy through solvent in a passive way. Therefore, minimal solvent or solvent-free condition facilitates the direct exposure of reactant to the radiation. Such increased reactivity is the important factor in the MW-synthesis, because the desired product is obtained very rapidly. The possible explanation for the formation of the products in short time lies in the fact that, due to its powers, MW provides elevated heating rates and accelerated reaction times. Therefore, reactant molecules come under the exposure of radiation directly. Another point is the interaction of the reactant with the electric vector of the radiation in the transition state enhances its stabilization remarkably and lowering the energy of activation compared to the classical heating method.

From the previous discussions it is very clear that the synthesis and applications of the said class of compounds such as oxindoles (3a-d), Schiff-base (2a-d), and thiadiazoline spiro-compounds (1a-d) are becoming valuable and versatile class of compounds in the 
field of synthetic organic chemistry due to their interesting chemical and diversified biological properties. Therefore, a substantial research is required to cope with a planned chemical synthesis of those compounds in their significant quantity with high purity. Accordingly, applying Green Chemistry adopted synthetic procedure under MWconditions, a number of oxindoles and thiadiazoline spiro-compounds were synthesized in high yields and the said method was much more superior and advantageous over the classical heating method with regard to a very short reaction time, minimal solvent and higher yields of the products. Although the $\mathrm{H}_{2} \mathrm{SO}_{4}$ mediated cyclization under MWtechnique was found not to be a feasible way with prolong irradiation, a short pulseirradiation technique gave expected yields of the cyclized products. The reported work is also very important as because it deals with Green Chemistry, a prime environmental issue, to protect our planet from hazards posed by conventional chemistry practice.

\section{References}

1. H. M. Kingstone and J. H. Stephen, Am. Chem. Soc. 3, 5 (1997).

2. R. Gedye, F. Smith, K. Westaway, H. Ali, L. Baldisera, L. Laberge, and J. Rousell, Tetrahedron Lett. 27, 279 (1986). doi:10.1016/S0040-4039(00)83996-9

3. R. J. Giguere, T. L. Bray and S. M. Duncan, Tetrahedron Lett. 27, 4945 (1986). doi:10.1016/S0040-4039(00)85103-5

4. C. Strauss, Aust. J. Chem. 83 (1999). doi:10.1071/C98156

5. A. Loupy, A. Petit, J. Hamelin, F. T. Boullet, P. Jacquault and D. Mathé, Reviews-Update, Synthesis, 1213 (1998). doi:10.1055/s-1998-6083

6. M. M. Hossain, Y. Kawamura, K. Yamashita and M. Tsukayama, Tetrahedron 62, 8625 (2006). doi:10.1016/j.tet.2006.06.066

7. C. Giselle and A. Ferreira, J. Braz. Chem. Soc. 17, 1 (2006).

8. M. M. Hossain, N. Islam, R. Khan, and M. R. Islam, Bangladesh J. Pharmacol. 2, 66 (2007).

9. M. R. Islam, J. Abedin, and K. Khayer, Indian J. Chem. 40B, 240 (2001).

10. M. R. Islam, J. Abedin, M. M. Hossain, and H. Duddeck, J. Bangladesh Chem. Soc. 11, 71 (1998).

11. G. K. Jnaneshwara, A. V. Bedekar, and V. H. Deshpande, Synth. Commun. 29, 3627 (1999). doi:10.1080/00397919908085998

12. M. R. Islam and Mohammad Mohsin, Bangladesh J Pharmacol. 2, 7 (2007). 